\title{
Điểm lại các bài viết trên Tạp chí Cộng sản giai đoạn 2008-2010
}

\author{
Vương Quân Hoàng
}

Centre Emile Bernheim

Solvay Brussels School of Economics \& Management

Université Libre de Bruxelles

Email: qvuong@ulb.ac.be

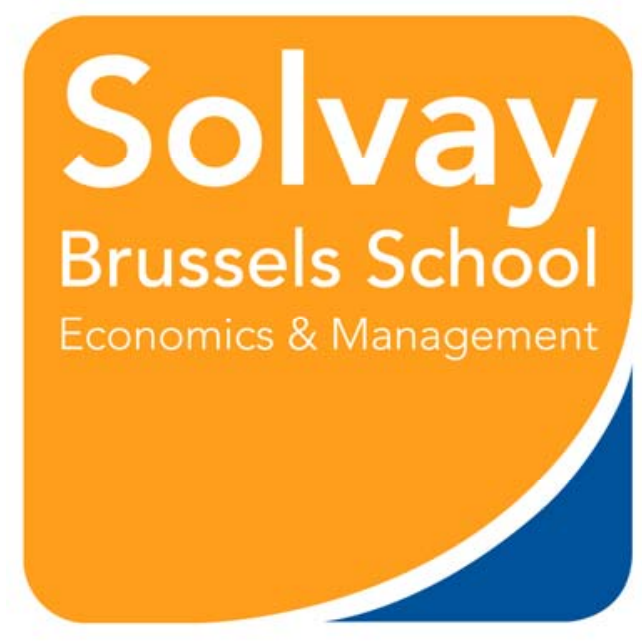

Ngày 1 tháng 1 năm 2012

Danh mục tài liệu tham khảo bên dưới liệt kê 10 bài viết của tôi trong giai đoạn từ năm 2008 tới 2011, đã đăng trên Tạp chí Cộng sản, Cơ quan Lý luận Chính trị của Ban Chấp hành Trung ương Đảng Cộng Sản Việt Nam. Tạp chí Cộng sản có lịch sử ra đời ngày 3 tháng 4 năm 1930, và lãnh đạo sáng lập chính là Chủ tịch Hồ Chí Minh, người khai sinh ra nhà nước Việt Nam Dân chủ Cộng hòa ngày 2 tháng 9 năm 1945.

(Một số thông tin về lịch sử ra đời và lãnh đạo tạp chí qua các thời kỳ có thể tham khảo tại địa chỉ: https://www.tapchicongsan.org.vn/web/guest/nhung-chang-uong-phat-trien) 


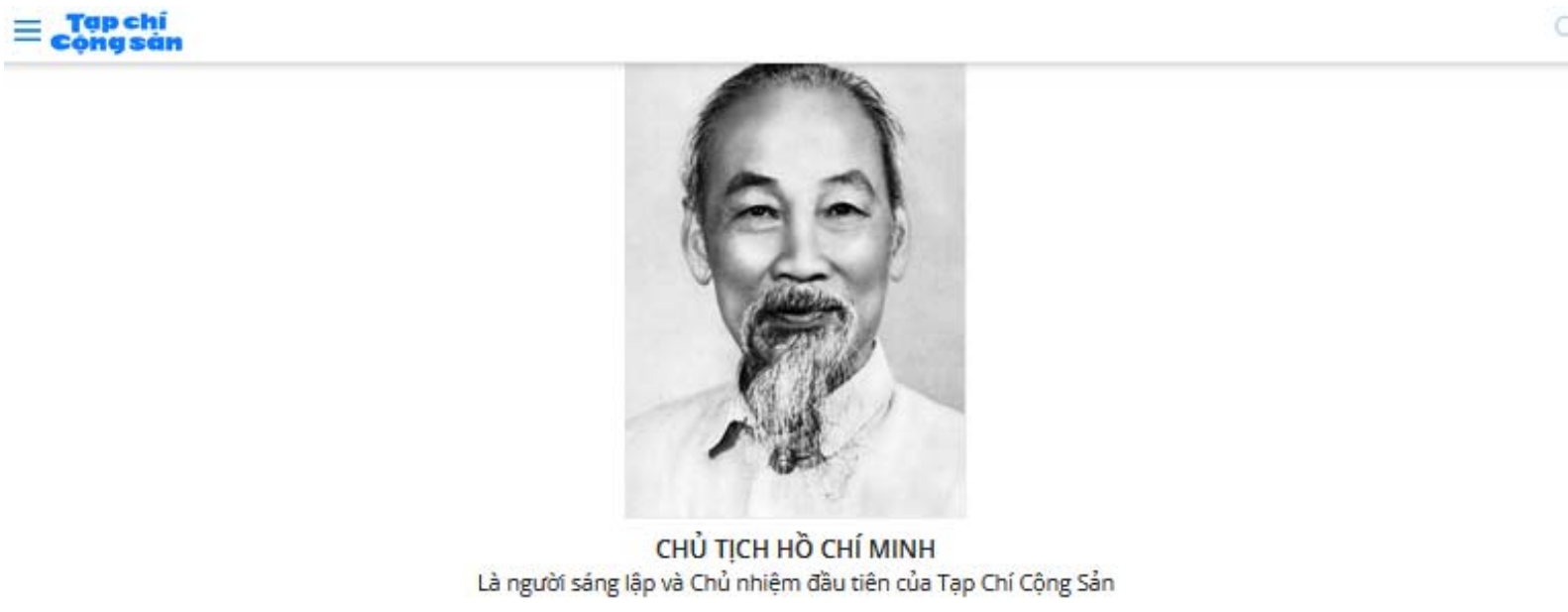

TỔNG BIÊN TẬP TẠP CHÍ CộNG SẢN QUA NHỮNG THờI KỲ

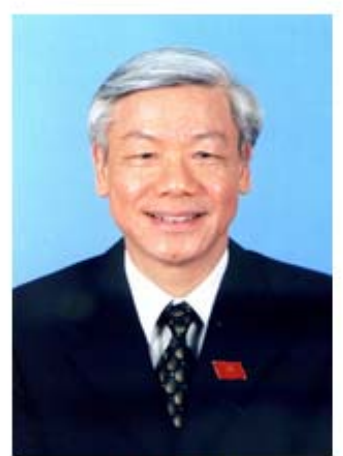

ĐồNG CHí

NGUYỄN PHÚ TRỌNG

(1991-1996)

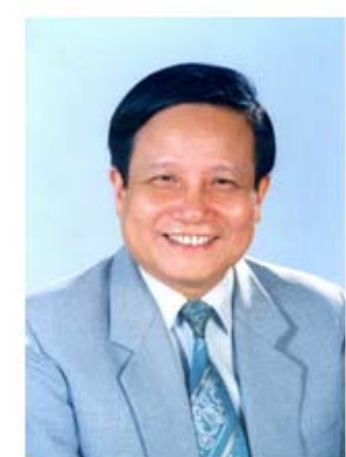

ĐồNG CHÍ

HÀ ĐĂNG

(1996-2001)

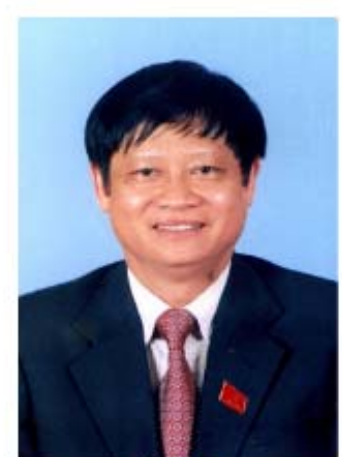

ĐồNG CHÍ

VŨ VĂN HIỀN

(2001-2002)

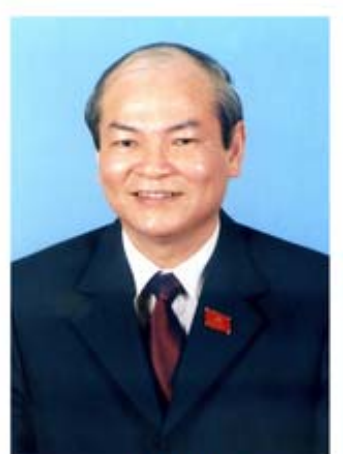

ĐồNG CHÍ

LÊ HỮU NGHĨA

(2003 - 2006)

Hình ảnh trang giới thiệu lịch sử Tạp chí Cộng sản tù̀ 1930; truy cập tại địa chỉ: https://www.tapchicongsan.org.vn/web/guest/nhung-chang-uong-phat-trien

Tất cả các bài viết của tôi được đăng trên Tạp chí Cộng sản giai đoạn 2008-2010 đều tập trung phản ánh, phân tích, và đề xuất giải pháp về các vấn đề kinh tế của đất nước, trong đó có một số có đề cập tới bối cảnh kinh tế quốc tế. Giai đoạn 2008-2010 là thời kỳ phản ánh những biến động mạnh và liên tục về cấu trúc động học vĩ mô cũng như vi mô. Lạm phát, thâm hụt cán cân vãng lại, bất cân đối vĩ mô, gia tăng khoảng cách thu nhập, và những đòi hỏi tiếp tục tìm kiếm mô hình tăng trưởng trong điều kiện mới là những vấn đề và đòi hỏi thường xuyên, ngày càng trở nên cấp bách.

Đặc biệt, bài viết thứ [10], cũng là bài cuối cùng trong danh mục, đề cập tới một trọng tâm kinh tế phải xử lý: Tập đoàn Công nghiệp Tầu thủy (Vinashin) thua lỗ đầu tư kéo dài và đạt tới ngưỡng tạo ra tác động dây chuyền tới hệ thống tài chính-ngân hàng. Hậu quả nghiêm trọng đã thúc đẩy đòi hỏi cải tổ việc quản trị chiến lược (governance) không riêng với Vinashin, mà nhìn chung toàn bộ hệ thống các tập đoàn kinh tế nhà nước đang có khuynh hướng đầu tư ngoài ngành, tập trung quá mức vào việc thu hút lực lượng kinh tế, mà không đầu tư đúng mức vào năng lực lõi và hệ thống giám sát hiệu quả vận hành. Không bao lâu sau, những chủ đề này cũng trở thành trọng điểm cả hệ thống 
kinh tế - chính trị quốc gia phải mất rất nhiều thời gian, công sức và cả nguồn lực để khống chế hậu quả, và tìm kiếm những giải pháp phòng ngừa trong tương lai.

Nói thêm về hình thức ấn phẩm xuất bản. Tới giai đoạn này, Tạp chí Cộng sản đã mở rộng cả hình thức ấn phẩm sang phiên bản điện tử, tức là trên trang web, và vẫn duy trì ấn phẩm truyền thống là bản tạp chí in giấy. Trong số 10 bài này, thì 6 đăng trên ấn phẩm giấy truyền thống, và 4 trên bản điện tử. Các bài đăng trên ấn phẩm in giấy sau đó cũng được xuất bản dưới dạng một bài báo điện tử, trên trang web tạp chí (tuy nhiên, ngày có thể khác so với ấn phẩm gốc và không có đánh số quyển, số serial và số trang in giấy).

* Ghi chú bổ sung: Các bài trên Tạp chí Cộng sản với nhóm chủ đề tập trung xung quanh kinh tế vĩ mô, kinh tế chính trị có liên quan mật thiết tới quá trình tập hợp suy nghĩ, tư liệu và xử lý dữ liệu cho cuốn sách Kinh tế Việt Nam: Thăng trầm và đột phá, do Nxb Chính trị Quốc gia Sự thật in và phát hành vào đầu tháng 6 năm 2009 [11]. Do đó, cũng không khó để nhận thấy một số bài báo liệt kê ở đây cũng xuất hiện trong danh sách tài liệu tham khảo của cuốn sách nói trên.

\section{References}

[1] Vương Quân Hoàng, Nguyễn Hồng Sơn. (2008). Hậu quả của tín dụng bất động sản ở Mỹ và nghĩ về các biện pháp phòng ngừa ở Việt Nam. Tạp Chí Cộng Sản, 79(784), 123-127.

[2] Nguyễn Hồng Sơn, Vương Quân Hoàng. (2008). Về mối liên thông giữa thị trường bất động sản, vốn và tiền tệ. Tạp Chí Cộng Sản, 79(786), 56-62.

[3] Phạm Minh Chính, Vương Quân Hoàng. (2008, May 15). Bảy dấu hiệu cảnh báo cần lưu ý để ổn định nền tài chính quốc gia. Tạp Chí Cộng Sản.

https://tapchicongsan.org.vn/web/guest/nghien-cu/-/2018/1420/bay-dau-hieu-canhbao-can-luu-y-de-on-dinh-nen-tai-chinh-quoc-gia.aspx

[4] Phạm Minh Chính, Vương Quân Hoàng. (2008, October 15). Những thời kỳ biến động của nền kinh tế Việt Nam: Bản chất của vấn đề và giải pháp cho tương lai. Tạp chí Cộng sản, 79(792). https://tapchicongsan.org.vn/web/guest/hoat-ong-cua-lanh-ao-ang-nha-nuoc/2018/3339/muc-luc-tap-chi-cong-san-so-792-\%2810-2008\%29.aspx

[5] Vương Quân Hoàng. (2009, January 22). Nhìn lại nền kinh tế Việt Nam 2008 phải trong bối cảnh khủng hoảng tài chính thế giới. Tạp chí Cộng sản, 80(795). https://tapchicongsan.org.vn/nghien-cu/-/2018/1961/nhin-lai-nen-kinh-te-viet-nam2008-phai-trong-boi-canh-khung-hoang-tai-chinh-the-gioi.aspx

[6] Vương Quân Hoàng. (2009, March 11). Một khuyến nghị cho tăng trưởng kinh tế Việt Nam trong khó khăn của khủng hoảng kinh tế - tài chính toàn cầu. Tạp chí Cộng sản. https://tapchicongsan.org.vn/web/guest/nghien-cu/-/2018/954/mot-khuyen-nghi-chotang-truong-kinh-te-viet-nam-trong-kho-khan-cua-khung-hoang-kinh-te---tai-chinh-toancau.aspx 
[7] Vương Quân Hoàng. (2009, March 26). Các siêu ngân hàng và áp lực cải tổ hệ thống ngân hàng. Tạp Chí Cộng Sản. https://tapchicongsan.org.vn/web/guest/nghien-cu/-/2018/2455/cacsieu-ngan-hang-va-ap-luc-cai-to-he-thong-ngan-hang.aspx

[8] Vương Quân Hoàng. (2009, April 28). Kinh tế thế giới với Trung Quốc là một trụ cột. Tạp chí Cộng sản. https://tapchicongsan.org.vn/web/guest/nghien-cu/-/2018/2627/kinh-te-thegioi-voi-trung-quoc-la-mot-tru-cot.aspx

[9] Vương Quân Hoàng. (2010). Kinh tế Việt Nam 2009 và một vài suy nghĩ về nhận thức luận chuyển đổi. Tạp chí Cộng sản, 81(1), 49-55.

https://tapchicongsan.org.vn/web/guest/nghien-cu/-/2018/315/kinh-te-viet-nam-2009va-mot-vai-suy-nghi-ve-nhan-thuc-luan-chuyen-doi.aspx

[10] Vương Quân Hoàng. (2010). Tái cấu trúc Vinashin: Cần đối xứng thông tin về hoạt động của doanh nghiệp. Tạp chí Cộng sản, 81(12), 40-44.

https://tapchicongsan.org.vn/web/guest/nghien-cu/-/2018/2253/tai-cau-truc-vinashin-can-doi-xung-thong-tin-ve-hoat-dong-cua-doanh-nghiep.aspx

[11] Phạm Minh Chính, Vương Quân Hoàng. (2009). Kinh tế Việt Nam: Thăng trầm và đột phá. Nxb Chính trị Quốc gia, Hà Nội. 